\title{
PLANEJAMENTO E ORÇAMENTO PLURIANUAIS: MECANISMOS COMPLEMENTARES OU SUBSTITUTOS?'
}

\author{
Constantino Cronemberger Mendes ${ }^{2}$ \\ Welles Matias de Abreu ${ }^{3}$ \\ Thiago Silva e Souza ${ }^{4}$
}

\section{INTRODUÇÃO}

O Plano Plurianual (PPA) para o período 2020-2023 foi aprovado pelo Congresso Nacional, promulgado como Lei no ${ }^{13.971}$, de 27 de dezembro de 2019, e publicado no Diário Oficial da União, em 30 de dezembro de 2019. O único veto presidencial decorre da alegada inconstitucionalidade da proposta legislativa de incorporar os Objetivos de Desenvolvimento Sustentável (ODS) como metas do planejamento e orçamento nacional. De fato, a adoçáo das metas setoriais nos programas do novo plano e nas suas ações orçamentárias é compatível com aquelas previstas nos ODS, não sendo adequado ampliar a rigidez da aplicação legal, obrigatória, com referência a acordos internacionais de natureza específica interna ou nacional, por meio do PPA ou do orçamento.

Um ponto essencial na discussão sobre o novo PPA 2020-2023, porém, está na possível extinção do instrumento de planejamento público plurianual de médio prazo, ao final de 2023, e na transição para um novo modelo orçamentário plurianual. A proposta trata de restringir o processo orçamentário às diretrizes orçamentárias (Lei de Diretrizes Orçamentárias - LDO), agora plurianuais, e aos orçamentos anuais (Lei Orçamentária Anual - LOA). Nesse sentido, trata-se de questionar a necessidade ou não de extinção do PPA, substituindo-o por um mecanismo de orçamento plurianual. Entendendo-se, com isso, que o modelo brasileiro de plurianualidade orçamentária poderia se aproximar de outros modelos adotados em diversos países desenvolvidos, inseridos na denominada estrutura metodológica Medium Term Framework (MTF) ou Abordagem de Médio Prazo. ${ }^{5}$

\footnotetext{
1. DOl: http://dx.doi.org/10.38116/brua22art4

2. Técnico de planejamento e pesquisa na Diretoria de Estudos e Políticas Regionais, Urbanas e Ambientais (Dirur) do Ipea; e ex-subsecretário de planejamento governamental do Ministério da Economia.

3. Analista de planejamento e orçamento da Secretaria de Orçamento Federal (SOF); coordenador na Auditoria Interna da Agência Nacional de Águas (ANA).

4. Capitão de Corveta; subcoordenador adjunto de orçamento na Secretaria-Geral da Marinha.

5. Essa abordagem assume diversas feições ou etapas, sendo restritas a questões fiscais (MTFisca/F), orçamentárias (MTBudgetaryF), de despesas (MTExpenditureF) e/ou de resultados (MTPerformanceF). Para uma discussão conceitual detalhada, ver Fortis e Gasparini (2017) e World Bank (2013).
} 
Alguns modelos de plurianualidade orçamentária são encontrados no conceito inglês do carry over, comparado ao controverso "restos a pagar" brasileiro, e no orçamento plurianual de investimentos (OPI) americano, aproximado da experiência brasileira adotada no final dos anos 1960, que se mostrou frágil como instrumento de planejamento nacional. O modelo australiano de projeçôes fiscais e orçamentárias é o que mais se aproxima do caso brasileiro, considerando as semelhanças com as definiçóes de escolhas prioritárias do PPA e as diretrizes fiscais e orçamentárias presentes na LDO ${ }^{6}$ A pergunta, entáo, é: qual o modelo MTF ideal para o Brasil?

A proposta de extinção do PPA e de adoção do orçamento plurianual (LDO plurianual ou PPA “rolante") foi apresentada pelo Ministério da Economia, em 30 de agosto de 2019 (Brasil, 2019, p. 6), sem um debate amplo anterior sobre suas implicaçóes e sem uma proposta concreta sobre a nova estrutura da LDO plurianual - LOA, em alternativa ao tripé PPA-LDO-LOA adotado desde a Constituição Federal de 1988. Na prática, o que se entende da proposta é que os instrumentos LDO e PPA seriam fundidos, sendo constituído um único mecanismo "orçamento plurianual" ou "PPA rolante" - unindo as diretrizes e os cenários fiscais, as projeçóes macroeconômicas e as metas e prioridades plurianuais aos orçamentos anuais.

A reação silenciosa por parte do setor público como um todo demonstra, de um lado, a real necessidade de se rever o papel e a estrutura do PPA ou do próprio planejamento de médio e longo prazos e, de outro, a incerteza e o desconhecimento sobre o que significa um mecanismo de orçamento plurianual adaptado ao caso brasileiro, considerando os diversos modelos aplicados no mundo. A decisão unilateral do Ministério da Economia sobre a mudança de modelo aparenta estar associada mais à necessidade de adoção de um programa de ajuste fiscal de médio e longo prazos do que de efetuar uma revisáo do planejamento de médio e longo prazos que compatibilize a capacidade do Estado na provisão de bens e serviços públicos às demandas sociais específicas do país.

Os objetivos principais deste texto são, portanto, demonstrar as diferenças entre os dois instrumentos (planejamento plurianual e orçamento plurianual) e apresentar possíveis implicaçóes e riscos de se adotar os dois mecanismos substitutos e não complementares dentro do processo político de decisão pública.

Planejar, em termos de fundamento para a decisão de política pública, significa escolher, priorizar, orientar o orçamento (seja anual, seja plurianual) na alocação e na distribuição de recursos públicos que atendam aos interesses e às necessidades ou demandas da sociedade. As escolhas públicas de médio prazo e as negociaçôes e decisões políticas consequentes são estabelecidas considerando as prioridades na agenda de governo e as restriçóes orçamentárias no período do mandato executivo. No horizonte de longo prazo, o planejamento governamental de médio prazo é ajustado a cada quatro anos, procurando manter a visão de futuro do país. ${ }^{7}$

No caso brasileiro, em especial, o papel do planejamento na escolha pública prioritária é essencial dadas as demandas sociais heterogêneas (diferentes interesses e objetivos setoriais alocativos) e desiguais (diferentes situaçôes e condiçôes sociais e regionais distributivas).

\footnotetext{
6. Note-se que qualquer modelo adotado está condicionado pela estrutura federativa específica de cada país, sendo o inglês (parlamentar-monárquico e centralizado) o que mais se distancia do brasileiro (presidencial-republicano e federativo-descentralizado), apesar de sua possível aplicação na ideia (restrita) de orçamento plurianual ou de PPA "rolante". A Austrália e os Estados Unidos, mesmo sendo países federativos, possuem modelos de relações entre os entes federados bastante distintos do Brasil. Para uma discussão dos modelos federativos no mundo, ver Poirier, Saunders e Kincaid (2015). 7. Daí a diferença entre os conceitos de Estado (longo prazo) e governo (curto e médio prazos). Ver Bobbio (2017).
} 
A oferta de bens e serviços públicos deve sempre tentar atender à demanda social, em complemento aos bens e serviços ofertados pelo setor privado.

A função primordial de um orçamento plurianual, diferentemente de constituir escolhas públicas estratégicas compatíveis com as demandas sociais, é proporcionar uma consistência fiscal intertemporal de médio e longo prazos entre a arrecadação e a execução dos recursos e dos incentivos públicos. As diretrizes fiscais e as prioridades, mesmo que plurianuais, dizem respeito não direta ou propriamente a problemas alocativos e distributivos de bens e serviços públicos adequados às necessidades sociais, mas, sim, aos problemas fundamentais do equilíbrio fiscal macroeconômico e da redução dos custos associados ao uso dos recursos públicos.

A abordagem alocativa, distributiva e de priorização do planejamento orçamentário plurianual refere-se tão somente à definição de níveis orçamentários (setoriais) e de composição da despesa pública. Desse modo, nos moldes do denominado na literatura como expenditure review ${ }^{8}$ o exame do gasto público entre setores, programas e projetos está associado aos resultados da sua execuçáo, ou seja, ao bom uso dos recursos públicos. Assim, os objetivos principais do planejamento orçamentário plurianual têm, na realidade, correspondência com a disciplina fiscal, a eficiência alocativa e técnica. Essas noçôes de eficiência, por sua vez, estão mais ligadas ao contexto da oferta pública e não necessariamente da leitura e problematização da estrutura da demanda social no país. Isso significa que o instrumento de orçamento plurianual está mais associado ao conceito de transparência fiscal (IMF, 2007) do que de planejamento per se.

Ao se confundir as funçóes básicas do setor público (alocativa, distributiva e de equilíbrio), restringindo-as ao âmbito fiscal, a proposta do Executivo de extinguir o PPA e de tornar a LDO um instrumento de diretrizes orçamentárias e de consistência orçamentária plurianuais, de fato, delega ao Legislativo a tarefa de definir as escolhas públicas, ou seja, de planejar. Isso não é um problema, dado que as escolhas públicas são definidas dentro de um processo de negociação política e de problematização das necessidades sociais, em que os critérios de priorização na alocação e distribuição de recursos públicos precisam ser explicitados de acordo com a compatibilização entre as demandas e as escolhas setoriais específicas.

A despeito da função constitucional delegada ao Congresso Nacional, de representar politicamente a sociedade - de forma restrita e fragmentada, contudo - e, portanto, de poder "escolher" por ela o que o setor público precisa ofertar para atender aos seus interesses e às suas demandas e necessidades, isso não retira do Executivo a sua responsabilidade de planejar, dentro de uma visão mais orgânica ou sistêmica e integrada de país. As escolhas públicas estratégicas, no médio prazo, estão associadas essencialmente à agenda governamental de prioridades, que se adequa a cada quatro anos, de acordo com as condiçóes fiscais vigentes e ao objetivo de atender minimamente às demandas sociais específicas.

A extinçâo do PPA não seria suficiente para eximir o Executivo do dever de planejar, pautado em uma visão mais integrada e sistêmica do país. Afinal, a Constituição Federal de 1988 determina, a começar do art. 21, que trata das competências da União, em seu inciso IX, a responsabilidade de "elaborar e executar planos nacionais e regionais de ordenação do território e de desenvolvimento econômico e social" (Brasil, 1988). Nesse sentido, da forma como foi apresentada a decisão do Ministério da Economia, a LDO plurianual (ou PPA "rolante") terá de ser totalmente adaptada para incorporar as funçóes de planejamento,

8. Ver Boueri, Rocha e Rodopoulos (2015) e Pradhan (1996). 
alocativa e distributiva - nos termos sociais e políticos aqui destacados, diferenciados da visão fiscal e técnica ou, melhor dizendo, fiscalista ou de custo-benefício econômico -, além da tradicional função de zelar pelo equilíbrio orçamentário e financeiro do setor público, em complemento à Lei de Responsabilidade Fiscal (LRF).

A possível ideia de simplificação do trâmite de propostas orçamentárias executivas restrita, em vez de três, a dois projetos de lei (LDO plurianual e LOA), não exclui a possibilidade de tornar o trâmite da LDO plurianual mais complexo e sujeito a se tornar um dispositivo altamente extensivo. Note-se que a LDO para 2020 (Lei nº-13.898, de 11 de novembro de 2019) possui atualmente mais de 60 páginas e 150 artigos, além de 8 anexos. No que diz respeito à função de planejamento (alocativo e distributivo), em particular, a LDO deverá ser totalmente revista - pelo menos os seus capítulos II (metas e prioridades da administração púbica), III (estrutura e organização dos orçamentos) e IV (diretrizes para elaboração e execução dos orçamentos da união) - para se tornar um orçamento plurianual ou um PPA "rolante".

A capacidade de tornar o planejamento governamental um instrumento útil e integrado ao orçamento plurianual implica colocá-lo em uma posição relevante de coordenador e orientador das escolhas estratégicas da ação pública, complementado pelas tarefas de monitoramento e avaliação de resultados da execução físico-financeira, e não apenas de consolidador de açôes orçamentárias consistentes ao longo do tempo. Os ajustes nas escolhas públicas prioritárias diante das mudanças nas necessidades sociais e no ambiente macroeconômico e orçamentário-financeiro não devem tornar o instrumento de planejamento governamental de médio prazo um elemento passivo ao orçamento (plurianual) e ao planejamento estratégico (administrativo) $)^{9}$ setorial.

$\mathrm{Na}$ estrutura orçamentária atual, o orçamento prescinde do planejamento público, na medida em que se ajusta a qualquer modelo de PPA. Existe no orçamento, em certa medida, uma atividade contínua de ajuste incremental anual (ou plurianual) das fontes e usos de recursos públicos, com objetivo principal de adequar as açóes programadas a qualquer modelo de PPA proposto, dada a disponibilidade de recursos públicos. Isso não significa que o planejamento é desnecessário, mas, sim, que o orçamento atingiu uma autonomia descolada do objetivo maior de definir prioridades e escolhas públicas compatíveis com as demandas sociais, ou seja, planejar.

A transiçâo para um novo modelo de orçamento plurianual não resolve a lacuna da falta de um planejamento nacional de ação pública compatível com as demandas sociais. Para isso, é necessário unir a ideia de plurianualidade orçamentária com a de um planejamento moderno e flexível, pautado na definição de critérios consistentes para as escolhas públicas, orientadores para a execução das açôes públicas. Não se trata de centralizar no Executivo a decisão sobre o planejamento nacional, nos moldes dos Planos Nacionais de Desenvolvimento (PNDs) anteriores. Como observado em World Bank (1998, p. 32) "na ausência de um efetivo processo de tomada de decisão, a política e o planejamento estarão desconectados entre si e com o orçamento, e eles não serão limitados pela disponibilidade de recursos ou por prioridades estratégicas". ${ }^{10}$

9. Para entender a diferença entre planejamento governamental, orçamento e planejamento estratégico administrativo ver Crepaldi e Crepaldi (2013), Toni (2016) e Giacomoni (2019).

10. "In the absence of effective decision-making processes, policy making and planning are disconnected from each other and from budgeting, and they are not constrained by resource availability or by strategic priorities". 
Sem dúvida, a ideia de orçamento plurianual, com aderência a um modelo do tipo MTF, contém uma preocupação legítima com a gestão orçamentária plurianual e a consistência intertemporal das finanças públicas. Isso, no entanto, não estaria necessariamente relacionado ao planejamento governamental ativo e flexível, como aqui destacado, dado que o MTF lida basicamente com questóes fiscais, orçamentárias e de execução das despesas públicas. Estas são fundamentais para o estabelecimento de prioridades e de alocação de recursos, mas não compreendem, per se, a consolidação das escolhas públicas prioritárias necessárias à ação pública. No contexto atual, trata-se de propor um modelo mais flexível, de adaptação, de acordo com as agendas prioritárias governamentais e as condições fiscais vigentes, mantendo, porém, a consistência dentro de uma visão de futuro, de longo prazo, para o desenvolvimento do país.

Portanto, a despeito das diferenças entre si, os instrumentos de planejamento e de orçamento plurianuais não prescindem um do outro. Os dois mecanismos são complementares, não substitutos. Os riscos de se adotar um mecanismo de orçamento plurianual, descolado do planejamento, significa retirar do Estado a capacidade de fazer escolhas prioritárias e estratégicas compatíveis com as necessidades e demandas sociais heterogêneas e desiguais. A adoção da ideia do PPA "rolante" ou LDO "plurianual", dadas as experiências internacionais, poderá tornar o orçamento público um instrumento meramente adaptativo às escolhas fragmentadas, mesmo que legítimas, do Poder Legislativo - e o Poder Executivo perderá definitivamente a sua já pequena capacidade de orientar as escolhas públicas em prol de uma visão mais sistêmica e integrada de país, compatível com demandas sociais específicas.

Em conclusão, a proposta do Ministério da Economia, de extinção do PPA sem uma devida discussão ou proposição de uma nova estrutura de planejamento e orçamento de médio prazo, poderá vir a ser um retrocesso ao modelo tríade atual, certamente imperfeito e limitado. O fato é que o Brasil, mais uma vez, ao tentar se aproximar das experiências e dos modelos internacionais, acaba "jogando fora a água suja da banheira com o bebê dentro" por não saber lidar com sua própria especificidade social, econômica e política. Em vez de rever um instrumento importante de planejamento de médio prazo, como o PPA, que tem função complementar à LDO, ou algo como uma LDO plurianual, o governo atual prefere o que parece ser mais simples, extinguir algo que não foi, ainda, efetivamente aplicado na sua concepção flexível e integrada das funçóes públicas alocativa e distributiva. Mais do que "reinventar a roda" o país prefere "importar a roda", sem se importar com as "estradas" próprias e particulares que precisa trilhar para uma ação pública eficaz, efetiva e eficiente.

\section{REFERÊNCIAS}

BOBBIO, N. Estado, governo, sociedade: fragmentos de um dicionário político. 20. ed. São Paulo: Paz e Terra, 2017. 253 p.

BOUERI, R.; ROCHA, F.; RODOPOULOS, F. (Org.) Avaliaçáo da qualidade do gasto público e mensuraçáo da eficiência. Brasília: Secretaria do Tesouro Nacional, 2015. 463 p.

BRASIL. Constituiçâo da República Federativa do Brasil de 1988. Diário Oficial da Uniáo, Brasília, 5 out. 1988. Seção 1.

Ministério da Economia. Consolidação fiscal expansionista no Brasil. Brasília: Secretaria Especial da Fazenda, dez. 2019. Disponível em: <https://www.gov.br/economia/pt-br/centraisde-conteudo/publicacoes/notas-informativas/2019/nota_ajuste_expansionista_31_12_2019. pdf/view>. Acesso em: 7 jan. 2020. 
CREPALDI, S. A.; CREPALDI, G. S. Orçamento público: planejamento, elaboração e controle. São Paulo: Saraiva, 2013. 248 p.

FORTIS, M. F. A.; GASPARINI, C. E. Plurianualidade orçamentária no Brasil: diagnóstico, rumos e desafios. Brasília: Enap, 2017. 338 p.

GIACOMONI, J. Orçamento governamental: teoria, sistema, processo. São Paulo: Atlas, 2019. $326 \mathrm{p}$.

IMF - INTERNATIONAL MONETARY FUND. Manual on fiscal transparency. Washington: IMF, 2007.

POIRIER, J.; SAUNDERS, C.; KINCAID, J. (Ed.). Intergovernmental relations in federal systems: comparative structures and dynamics. Canada: Oxford University Press, 2015. 511 p.

PRADHAN, S. Evaluating public spending: a framework for public expenditure reviews. Washington: World Bank, 1996. (World Bank Discussion Papers, n. 323).

TONI, J. de. $\mathbf{O}$ planejamento estratégico governamental: reflexôes metodológicas e implicaçóes na gestão pública. Curitiba: InterSaberes, 2016. 393 p.

WORLD BANK. Public expenditure management handbook. Washington: The World Bank, 1998.

Beyond the annual budget: global experience with medium term expenditure frameworks. Washington: The World Bank, 2013. 